\section{BMJ Paediatrics Open}

\title{
Swim drink study: a randomised controlled trial of during-exercise rehydration and swimming performance
}

Graham L Briars, ${ }^{1,2}$ Gillian Suzanne Gordon, ${ }^{3}$ Andrew Lawrence, ${ }^{4}$ Andrew Turner, ${ }^{4}$ Sharon Perry, ${ }^{4}$ Dan Pillbrow, ${ }^{4}$ Florence Einstein Walston, ${ }^{1,2}$ Paul Molyneux ${ }^{5}$

To cite: Briars GL, Gordon GS, Lawrence A, et al. Swim drink study: a randomised controlled trial of duringexercise rehydration and swimming performance. BMJ Paediatrics Open 2017;1:e000075. doi:10.1136/ bmjpo-2017-000075

- Additional material is published online only. To view please visit the journal online (http://dx.doi.org/10.1136/ bmjpo-2017-000075).

Received 9 May 2017

Revised 29 September 2017 Accepted 29 September 2017

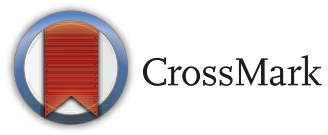

${ }^{1}$ Paediatric Gastroenterology, Norfolk and Norwich University Hospital NHS Foundation Trust, Norwich, UK

${ }^{2}$ Faculty of Medicine and Health Sciences, University of East Anglia, Norwich, UK

${ }^{3}$ Community Paediatrics, Child Development Centre, Bury St Edmunds, UK

${ }^{4}$ West Suffolk Swimming Club, Bury St Edmunds, UK

${ }^{5}$ Neurology, Addenbrooke's

Hospital, Cambridge, UK

Correspondence to Dr Graham L Briars; g.briars@ doctors.org.uk

\section{ABSTRACT}

Objective To determine whether during-exercise rehydration improves swimming performance and whether sports drink or water have differential effects on performance. Design Randomised controlled multiple crossover trial. Setting A UK competitive swimming club.

Subjects 19 club-level competitive swimmers, median age (range) $13(11-17)$ years

Interventions Subjects were scheduled to drink ad libitum commercial isotonic sports drink ( $3.9 \mathrm{~g}$ sugars and $0.13 \mathrm{~g}$ salt per $100 \mathrm{~mL}$ ) or water (three sessions each) or no drink (six sessions) in the course of twelve $75 \mathrm{~min}$ training sessions, each of which was followed by a $30 \mathrm{~min}$ test set of ten $100 \mathrm{~m}$ maximum-effort freestyle sprints each starting at 3 min intervals.

Main outcome measure Times for the middle $50 \mathrm{~m}$ of each sprint measured using electronic timing equipment in a Federation Internationale de Natation (FINA)-compliant sixlane $25 \mathrm{~m}$ competition swimming pool.

Randomisation Software-generated individual random session order in sealed envelopes. Analysis subset of eight sessions randomly selected by software after data collection completed.

Masking Participants blind to drink allocation until session start.

Results In the analysis data set of 1118 swims, there was no significant difference between swim times for drinking and not drinking nor between drinking water or a sports drink. Mean (SEM) $50 \mathrm{~m}$ time for no-drink swims was 38.077 (0.128) $s$ and 38.105 (0.131) s for drink swims, $p=0.701$. Mean $50 \mathrm{~m}$ times were 38.031 (0.184) s for drinking sports drink and $38.182(0.186) \mathrm{s}$ for drinking water, $p=0.073$. Times after not drinking were $0.027 \mathrm{~s}$ faster than after drinking ( $95 \% \mathrm{Cl} 0.186 \mathrm{~s}$ faster to $0.113 \mathrm{~s}$ slower). Times after drinking sports drink were $0.151 \mathrm{~s}$ faster than after water $(95 \% \mathrm{Cl}$ $0.309 \mathrm{~s}$ faster to $0.002 \mathrm{~s}$ slower). Mean (SEM) dehydration from exercise was $0.42(0.11) \%$.

Conclusions Drinking water or sports drink over $105 \mathrm{~min}$ of sustained effort swimming training does not improve swimming performance.

Trial registration ISRCTN: 49860006.

\section{BACKGROUND}

Major bodies including the International Olympic Committee ${ }^{12}$ have recommended during-exercise rehydration, following expert

\section{What is already known on this topic?}

The International Olympic Committee advocates during-exercise rehydration where it is available in dehydrating exercise.

- In the absence of high-quality evidence supporting a benefit to the athlete, $£ 260 \mathrm{~m}$ is spent each year in the UK on sugar-containing sports rehydration drinks, much of which is consumed by children and young people.

\section{What this study hopes to add?}

Ad libitum isotonic sugar-containing and electrolyte-containing sports rehydration drinks do not confer any measurable performance benefit over ad libitum water in competitive adolescent swimmers.

- Ad libitum during-exercise rehydration does not confer any measurable performance benefit over abstention from drinking in competitive adolescent swimmers.

advice that athlete rehydration improves performance ${ }^{3}$ and that euhydration is appropriate in sporting pursuits. ${ }^{4}$ Resulting efforts to avoid dehydration have spawned widespread sports drink consumption predominantly in children and young people. Current estimated annual sales are $£ 260 \mathrm{~m}$ in the UK and US $\$ 2$ billion in the USA. ${ }^{5}$ However, the evidence used to support industry claims of benefit often employs surrogate measures of performance and is not of sufficient quality to inform the public about the benefits and harms of sports drinks. ${ }^{6}$

Stroke volume is reduced in dehydrated endurance athletes exercising in a $35^{\circ} \mathrm{C}$ environment, ${ }^{7}$ but not at $2^{\circ} \mathrm{C}^{8}$. Laboratory exercise to exhaustion studies report performance impairment with dehydration over $2 \%,{ }^{9}$ but field studies which more closely replicate the athlete's experience do not. These contrasts 
make dehydration prevention studies difficult to generalise. Such studies include ad libitum drinking incompletely correcting dehydration, ${ }^{10}$ flavouring variably increasing fluid intake ${ }^{11} 12$ and small non-randomised studies in swimming, ${ }^{13}$ and flat water kayaking ${ }^{14}$ reporting superior rehydration with sports drinks. Thus, empirical above-thirst rehydration regimens ${ }^{15}$ are difficult to justify. The UK regulatory authority, the Advertising Standards Agency, has not been convinced by the evidence and banned the use of a sports drink advertisement claiming a sports drink 'hydrates and fuels you better than water'. ${ }^{16}$

In addition to uncertain benefit, high drink intake may be harmful. Athletes have overhydrated themselves, ${ }^{13} 1718$ and this has precipitated hyponatraemia ${ }^{19}$ and death in runners. ${ }^{20}$ In the least active consumers, these sugar-sweetened beverages may contribute to energy imbalance and childhood obesity. ${ }^{21-24}$

With identified risks from overhydration, overnutrition and no proven benefit to date, we conducted a randomised controlled multiple crossover study in clublevel swimmers, using swimming times as our outcome variable, to answer three questions:

1. Does drinking during swimming improve performance?

2. Is isotonic sports drink better than water?

3. Are there idiosyncratic differences in response between individual athletes?

Pool swimming competitive events themselves are not of sufficient duration to cause dehydration severe enough to impair performance, unlike endurance events. ${ }^{4} 25$ Therefore, we conducted our testing in sustained training sessions.

\section{Subjects}

Swimmers were recruited from the West Suffolk Swimming Club, in the month preceding the start of the study, after personal and parental consent. All were free from illness, satisfied selection criteria for their training squad and trained six times per week.

\section{METHODS}

There were 12 Friday study sessions. At each, subjects completed $75 \mathrm{~min}$ of training. They then performed a test set of $10 \times 100 \mathrm{~m}$ maximum-effort freestyle sprints according to Federation Internationale de Natation (FINA) rules over $30 \mathrm{~min}$ continuing to have access to their designated drink regimen throughout the full 105 min.

\section{TEST SETS}

The sprints started at $3 \mathrm{~min}$ intervals, with a maximum of four swimmers per lane in a six-lane 25 m FINA-compliant pool. Consecutive swimmers in each lane started at $5-7 \mathrm{~s}$ intervals. Electronic timing pads (Daktronics) at the turn end were used to record swimmer touches. Times for the middle $50 \mathrm{~m}$ for each $100 \mathrm{~m}$ swim were determined by subtracting the recorded touch time after 25 from that at $75 \mathrm{~m}$ and recorded to the nearest $1 / 1000 \mathrm{~s}$. This approach eliminated reaction time and factors related to a dive start from our consideration. The four starting waves of swimmers wore different coloured hats and were monitored by officials on each lane. The turn end was under video surveillance throughout the test set as an adjunct to the timing equipment.

\section{DRINK ALLOCATION}

Bottles of sports drinks and mineral water with mouthpieces were purchased in bulk from a high street supermarket. The mineral water had no declared sodium or glucose content. The isotonic sports drink had declared carbohydrate (glucose and fructose) and salt contents of 3.9 and $0.13 \mathrm{~g} / 100 \mathrm{~mL}$, respectively. This was equivalent to $216 \mathrm{mM}$ glucose and $22 \mathrm{mM}$ sodium. We measured the sodium content of the water at $<20 \mathrm{mM}$ and sports drink at $26 \mathrm{mM}$ and the glucose contents at 0 and $207.4 \mathrm{mM}$, respectively.

For sessions numbered 1-6, subjects had no drink, sessions 7-9 sports drink and sessions 10-12 water. Each subject attended sessions 1-12 in an individually randomised order, so that on any study day a mix of session numbers were being performed.

Using online randomisation software, ${ }^{26}$ the study randomiser determined this individual random session order immediately following recruitment of all subjects. These designations were held in sealed envelopes. Swimmers were blinded to their session drink designation until their arrival on poolside at the start of that session. They were then under continuous supervision until the start of training and did not have an opportunity to drink anything other than their designated drink. The week's swimmer session number allocation was released to the study team 4 hours before the session.

Two catch-up sessions were available at the end of the study, when missed sessions could be performed. When more than two sessions had been missed, the two catch-up sessions that would allow maximum analytical comparison were completed. Missed sessions were considered for inclusion in the order that they were missed. The swimmer was not told of the drinking regimen for the catch-up session until arrival at the poolside.

\section{SUBJECT ASSESSMENT}

Swimmers were weighed to the nearest $10 \mathrm{~g}$ on electronic scales at the start and at the end of each session. They were prewetted for both measurements. They were permitted toilet breaks in the training session, if required. The volume of urine produced was estimated from swimmer weights immediately before and after their toilet break.

Two $500 \mathrm{~mL}$ preweighed labelled drink bottles were provided for each swimmer containing their designated drink with further preweighed labelled bottles available. Used drink bottles were weighed at the end of each 
training session to an accuracy of $1 \mathrm{~g}$. Swimmers allocated to a no-drink session were at liberty to request emergency fluid if they judged they needed it for their well-being. No swimmer made such a request.

Fluid intake, urine output and weight change over the session were used to determine the percentage dehydration caused by the exercise and state of hydration after exercise as modified by the drinking regimen.

\section{QUESTIONNAIRES}

Questionnaires were completed on study entry, study exit and before and after each session. The entry and exit questionnaires determined the swimmer's prediction and perception respectively of which drinking regimen would give their fastest and slowest swims, and on entry the presence of a personal or parental history of a migraine disorder was determined and their personal best time for $50 \mathrm{~m}$ freestyle was recorded.

Each presession and postsession questionnaire contained visual analogue scales to indicate degree of thirst and of tiredness (shown in online supplementary additional file 3). The presession document had a tick box for the presence of headache and abdominal pain.

\section{Analytical strategy}

We used SPSS V.17 for statistical analysis. Preliminary data (mean (SD) 50m time 29.725 (0.141) s) predicted with 80\% power $(\mathrm{p}<0.05)$ that 1560 analysed swims detects a difference between drinking and not drinking of $0.01 \mathrm{~s}$. Seven hundred and eighty swims detects $0.014 \mathrm{~s}$ difference between sports drink and water and 80 analysed swims per participant detects a difference between mean swim times of $0.045 \mathrm{~s}$ between the swims for the drinking regimens for the individual swimmer.

\section{Enrolment}

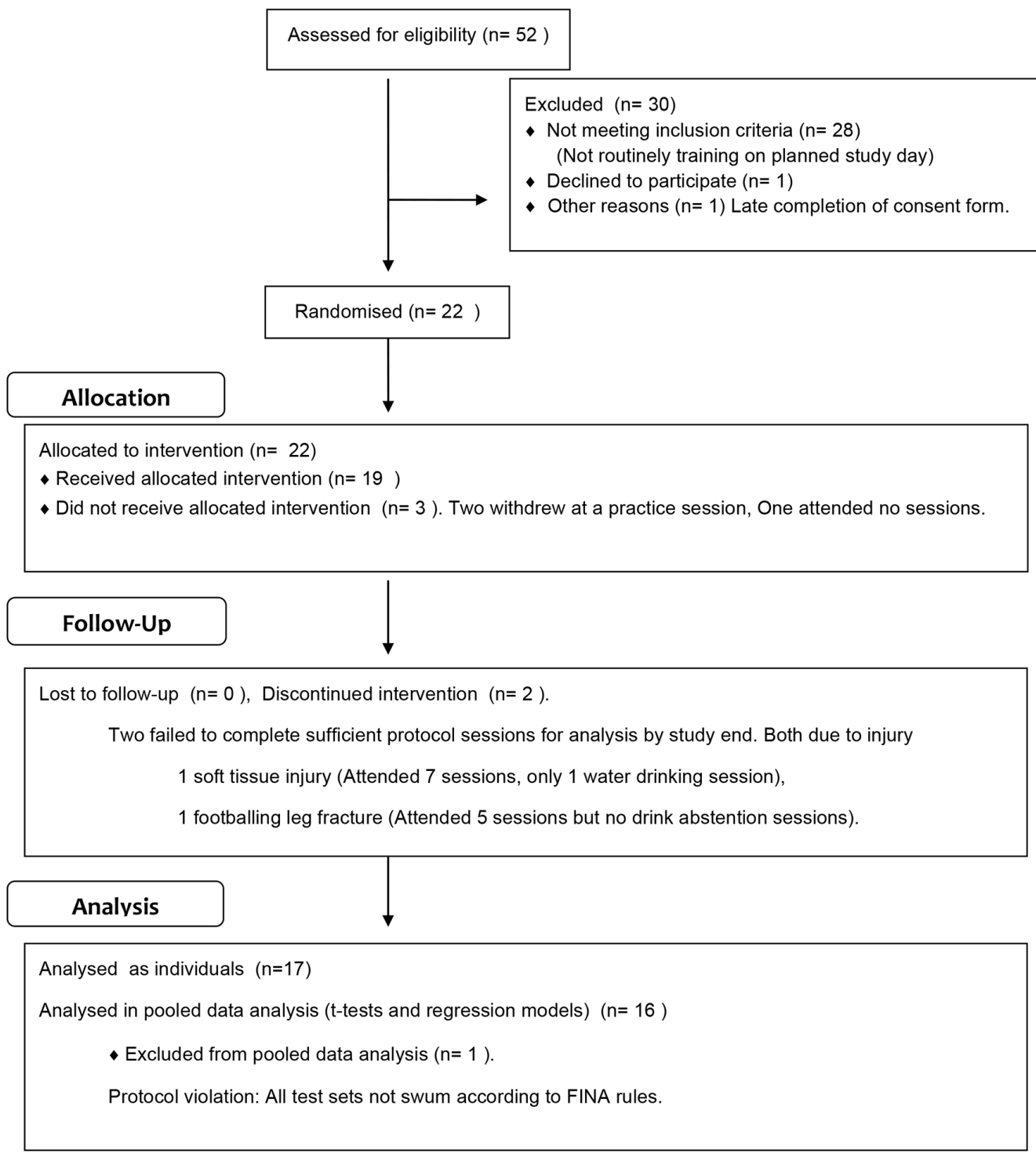

Figure 1 CONSORT flowchart for the randomised controlled multiple crossover trial of athletes drinking nothing, water or sports drink during exercise. 


\begin{tabular}{lll}
$\begin{array}{l}\text { Table } 1 \\
\text { as corrected by the dinking regime }\end{array}$ & $\begin{array}{l}\text { Mean Hydration status at the end of the session } \\
\text { bon-drinking (mean } \\
\text { \% (SEM)) }\end{array}$ & $\begin{array}{l}\text { Drinking (mean \% } \\
\text { (SEM)) }\end{array}$ \\
\hline All subjects & $-0.30 \%(0.16)$ & $+0.27 \%(0.17)$ \\
\hline Males & $-0.50 \%(0.25)$ & $+0.11 \%(0.27)$ \\
\hline Females & $-0.11 \%(0.19)^{\star}$ & $+0.43 \%(0.23)^{\star}$ \\
\hline & Water (mean \% & Sports drink (mean \% \\
& (SEM)) & (SEM)) \\
\hline All subjects & $+0.16 \%(0.24)$ & $+0.38 \%(0.27)$ \\
Males & $+0.04 \%(0.42)$ & $+0.18 \%(0.33)$ \\
\hline Females & $+0.43 \%(0.23)^{\star}$ & $+0.13 \%(0.34)^{\star}$ \\
\hline
\end{tabular}

*Underestimated dehydration resulting from increased postswim extracorporeal water in female subject's hair.

For each analysis (drink vs no drink and sports drink vs water), we paired sprint repetitions 1-10 with corresponding repetitions in their comparator and used repeated measures $\mathrm{t}$-test, with overall $\mathrm{p}<0.05$, using Bonferroni correction for individual data (critical $\mathrm{p}$ value $0.003)$.

We anticipated that, even with catch-up sessions, all participants may not be able to attend all 12 training sessions. We therefore planned a priori to analyse data from eight sessions selected by a block randomisation method after data collection. Once collected data were validated, a randomised session number list was generated. Sessions were selected in this order until each swimmer had four non-drinking sessions and two sessions for each drink selected. Swimmers attending all 12 training sessions would have 120 sprints, 80 of which were selected for analysis. The study staff remained blind to the analysis subset during data collection. Swimmers with $<80$ sprints completed had 40 selected.

\section{Regression models}

Linear regression models were constructed to explore relationships between swimming times and potential predictors. In the first model, $50 \mathrm{~m}$ swim time was the dependent variable, and the sprint repetitions were ranked from fastest to slowest across all swimmers. These ranks were used as one independent variable; the others were personal best time, study duration, sports drink, 1 for yes, 0 for no and water, 1 for yes, 0 for no. Each individual sprint was treated as being independent.

In a second regression model, with the swimmer's mean time for the 10 repetitions in each session, expressed as a percentage of their personal best time as the dependent variable, we explored the influence of three blocks of independent variables. The first was volume of sports drink and volume of water consumed in the session. The second, designed to reflect exercise severity, was training distance swam in the session, thirst and tiredness increases in the session, percentage dehydration attributable to exercise and coefficient of variation of
Table 2 Pooled data analysis

Drink (D) vs

Water (W) vs no drink (ND) sports drink (SD)

$\begin{array}{lll}\text { Seconds difference } & \text { D-ND time } & \text { W-SD time } \\ \text { between paired } & 0.027(0.186 \text { to } & 0.151(0.309 \text { to } \\ \text { swims Mean } & -0.113) & -0.002) \\ (95 \% \mathrm{CI}) & & \end{array}$

$50 \mathrm{~m}$ times

ND $38.077(0.128) \quad$ SD $38.031(0.184)$ (SEM)

\begin{tabular}{|c|c|c|}
\hline & D 38.105 (0.131) & W $38.182(0.186)$ \\
\hline \multirow{3}{*}{$\begin{array}{l}\text { Change in thirst } \\
\text { VAS } \\
\text { 10-point scale }\end{array}$} & $N D+1.96$ & $\mathrm{SD}+0.05$ \\
\hline & From 2.63 to 4.00 & From 4.84 to 4.90 \\
\hline & $\begin{array}{l}\text { D }-0.05 \\
\text { From } 4.84 \text { to } 4.77\end{array}$ & $\begin{array}{l}W-0.18 \\
\text { From } 4.83 \text { to } 4.65\end{array}$ \\
\hline \multirow{2}{*}{$\begin{array}{l}\text { Urine output } \mathrm{mL} / \mathrm{kg} \\
\text { Mean (SEM) }\end{array}$} & $N D<0.01(<0.01)$ & SD $1.02(0.50)$ \\
\hline & D $1.22(0.50)$ & W 1.54 (0.74) \\
\hline \multirow[t]{2}{*}{ Volume drunk $/ \mathrm{mL}$} & ND $0(0)$ & SD 488.0 (51.8) \\
\hline & D 409.0 (11.5) & W 339.8 (47.2) \\
\hline
\end{tabular}

VAS, visual analogue scale.

the swimmers' times in the session. We predicted that subjects undergoing a training session that they found intense may exhibit greater variation in their sprint times for that session. The final block reflected other external factors that we predicted might affect performance; these were pool temperature and duration of study.

\section{RESULTS}

The CONSORT diagram is shown in figure 1 . Of the 19 subjects, 8 (5 male) were from the most senior training squad (subject ID numbers less than 200) and 11 (5 male) from a lower squad. The mean (SD) session training distances throughout the study, excluding the test set, were 3211 (439) $\mathrm{m}$ for the top squad and 2311 (154) m for the lower squad. Median (range) age was 13 (11-17) years. Mean (SD) body mass index at recruitment was 17.47 (5.35). Data were collected for $1810 \times 50 \mathrm{~m}$ swims. The mean (SD) pool water temperature was $29.3^{\circ} \mathrm{C}$ $\left(0.15^{\circ} \mathrm{C}\right)$. The analytical set comprised 1118 swims, 40 pairs of swims from 12 subjects, 20 from 3 subjects and 19 from 1 subject. One pair of swims from the latter subject was excluded because of a FINA rule violation in one swim. The study sessions were completed over a 23-week period. Subject attendance is shown in online supplementary additional file 3. Across all swim sessions, the mean (SEM) dehydration generated by exercise was $0.42(0.11) \%$ body weight. Dehydration data are shown in table 1 .

\section{Normality of data}

On formal testing (Kolmogorov-Smirnov (K-S)), the times for the $50 \mathrm{~m}$ swims across the entire analysis data set did show significant variation from a normal distribution, 

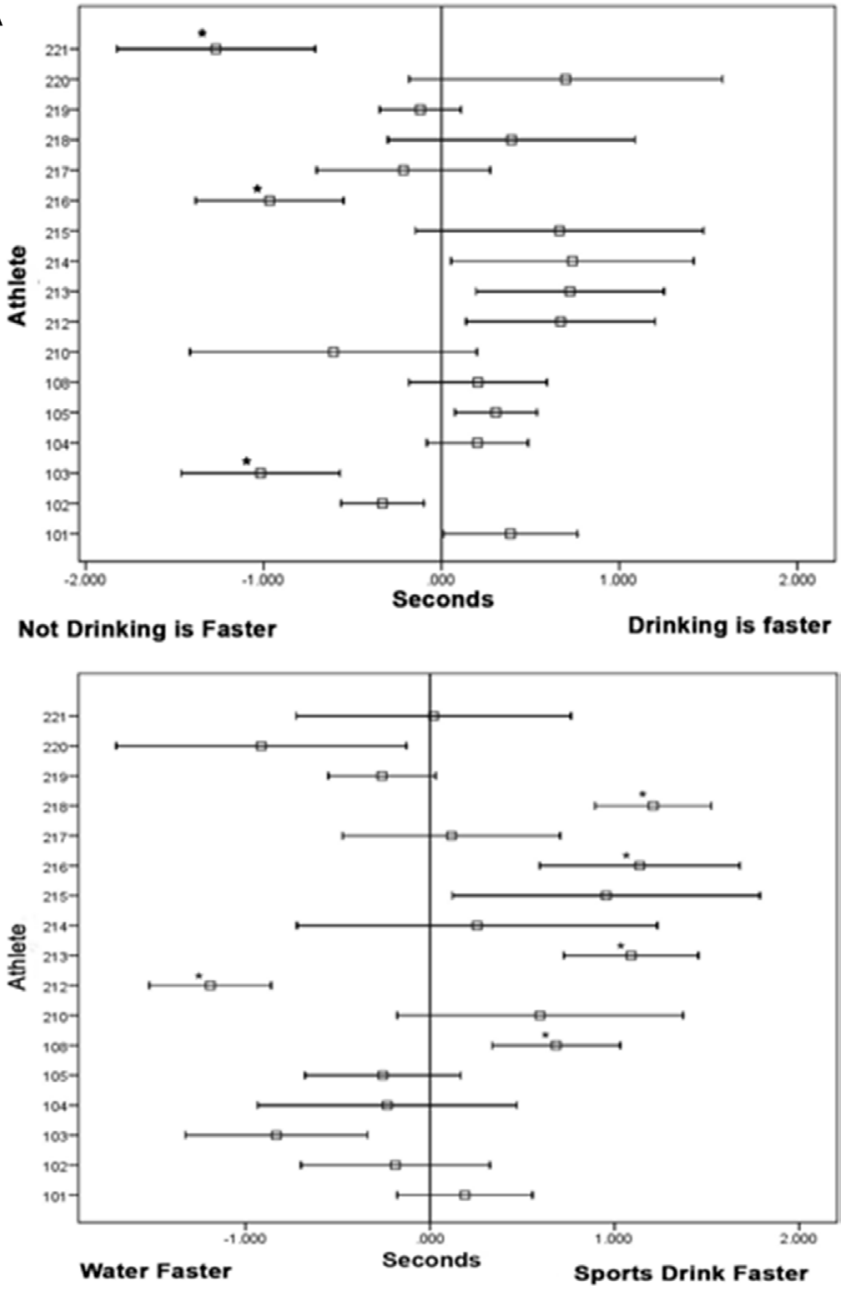

Figure 2 No athlete had a stepwise improvement in performance from drinking nothing, water and sports drink. Mean differences in $50 \mathrm{~m}$ swimming times across sets of paired swims (seconds mean $\pm 95 \% \mathrm{Cl}$ ); drinking versus not drinking (A), water versus sports drink (B). *Identify performance differences at critical Bonferroni level $(p<0.003$, repeated-measures t-test, SPSS V.17). Athlete 101 used a pull-buoy buoyancy aid throughout and is excluded from the main analysis because of resulting FINA rule violation.

whether expressed as percentage of personal best (K-S $0.61, \mathrm{p}=0.003$ ) or raw times (K-S 1.41, $\mathrm{p}<0.001$ ). On reviewing the normal $\mathrm{Q}-\mathrm{Q}$ plots, however, we judged that the variation from the normal distribution was not so great as to make parametric testing inappropriate and decided to accept the associated risk of type 1 error.

\section{Pooled data analysis}

Fifty metre times after not drinking were $0.027 \mathrm{~s}$ faster than after drinking $(95 \%$ CI $0.186 \mathrm{~s}$ faster to $0.113 \mathrm{~s}$ slower). Times after drinking sports drink were $0.151 \mathrm{~s}$ faster than after water $(95 \% \mathrm{CI} 0.309 \mathrm{~s}$ faster to $0.002 \mathrm{~s}$ slower). Accordingly, there were no significant differences in mean times for $50 \mathrm{~m}$ swims with and without drinks or between the two drinks in the associated training session (table 2).
Individual data analysis

Mean differences in $50 \mathrm{~m}$ times with $95 \%$ CIs are shown in figure 2 for drinking versus non-drinking sessions and for sports drink versus water. T-test results for the individual subjects are shown in online supplementary tables (online supplementary additional files 1 and 2).

Three subjects (103, 216 and 221) had significant differences in their swim times between drinking and not drinking. All were faster without drink. Four subjects (108, 213, 216 and 218) swam faster after sports drink and one (212) after water. These performance differences were unexplained by session training distance, pool temperature, duration of the study, thirst or tiredness measurements or by subject preconception or symptoms.

\section{REGRESSION MODELS \\ Model 1}

The ranks for repetitions $1-10$ were $4,8,3,2,6,5,7,9$, 10,1 . Regression coefficients are shown in table 3 . Only the coefficients for the swimmer's personal best time and repetition rank were significantly different from zero. This model accounted for $54.6 \%$ of the variation in recorded $50 \mathrm{~m}$ times.

\section{Model 2}

Coefficients for predicting the swimmer's mean $50 \mathrm{~m}$ swim time at the individual sessions, expressed as percentage of personal best time, are shown in table 3 .

Blocks 1, 2 and 3 accounted for 1.6\%, 19.7\% and $0.3 \%$ of the variation in $50 \mathrm{~m}$ times, respectively. The coefficients for volume of sports drink $(<0.001)$ and volume of water $(0.006)$ were not significantly different from zero ( $\mathrm{p}=0.918$ and 0.188 , respectively). Significantly predictive coefficients were limited to block 2 .

There was no relationship between volumes of fluid taken and performance.

Primary data are shown in online supplementary additional file 4 and described in online supplementary additional file 5 .

\section{DISCUSSION}

In this randomised controlled trial, we have measured swimming times to an accuracy of 10 times greater than required by FINA rules and used automated timing equipment to reduce observation bias. In common with the difficulties faced in surgical trials, ${ }^{27}{ }^{28}$ we were prevented from achieving full double blinding but took steps to maximise masking. Participants were blind to their drink allocation until they were supervised in the training session. We blinded the study staff to the subset of data for analysis and selected these data according to a predetermined protocol. We have shown no impact on our subjects' times for the middle $50 \mathrm{~m}$ of a series of maximum effort $100 \mathrm{~m}$ freestyle swims, irrespective of whether they drank nothing, a sports drink or water prior to their test set. We found no evidence that drinking or 
Table 3 Regression model coefficients

\begin{tabular}{|c|c|c|}
\hline Coefficient & (95\% Cls) & Variable name \\
\hline Model 1 & \multicolumn{2}{|c|}{ Fifty-metre swim times (s) } \\
\hline 4.62 & (2.82 to 6.42$)$ & Constant \\
\hline 1.09 & (1.04 to 1.15$)$ & Personal best time \\
\hline 0.61 & (0.018 to 0.103 ) & Rank order for individual repetition \\
\hline 0.18 & (-0.001 to 0.37$)$ & Study duration \\
\hline 0.67 & $(-234$ to 0.368$)$ & Sports drink, $1=y e s, 0=$ no \\
\hline-0.42 & $(-0.340$ to 0.256$)$ & Water, $1=$ yes, $0=$ no \\
\hline Model 2 & \multicolumn{2}{|c|}{ Swimmer's session mean $50 \mathrm{~m}$ swim time (as $\%$ of personal best time) } \\
\hline 211 & (-62 to 485$)$ & Constant \\
\hline$<0.001$ & $(-0.004$ to 0.006$)$ & Volume of sports drink \\
\hline 0.006 & (0.000 to 0.013$)$ & Volume of water \\
\hline-0.004 & $(-0.006$ to -0.001$)$ & Session training distance \\
\hline 0.222 & $(-0.422$ to 0.876$)$ & Increase in thirst \\
\hline 0.248 & $(-0.659$ to 1.156$)$ & Increase in tiredness \\
\hline 0.015 & $(-1.058$ to 1.088$)$ & Dehydration (\%) \\
\hline 2.607 & (0.908 to 4.305$)$ & $\begin{array}{l}\text { Swimmer's session coefficient of } \\
\text { variation for times }\end{array}$ \\
\hline-2.739 & $(-12.112$ to 6.635$)$ & Pool temperature \\
\hline 0.002 & $(-0.225$ to 0.229$)$ & Study duration (weeks) \\
\hline
\end{tabular}

the volume drunk influences these $50 \mathrm{~m}$ times in regression analyses. In these regression analyses, we did not use a repeated-measures technique, which may have given more accurate coefficients, but chose to confirm the influence of suspected non-drink predictors of performance in our first model and then exclude these in our second model by standardising times on the swimmer's personal best time, and aggregating a swimmer's session times into a single mean time.

In the individual subject analyses, there were performance differences between the drinking regimens for some subjects. Some of these suggested that performance was inferior with drinking. However, no subject had stepwise changes in performance that would suggest a biological effect of the drink. The absence of any effect of drinking regimen or drink volume on swim times in the regression models and the absence of any performance difference between drinking regimens in the pooled data strongly suggest that the significant differences seen in individual results are the result of an unidentified confounding factor.

We had anticipated that tiredness before training might have an impact on performance or that subjects with migraine, a condition affecting $10 \%-15 \%$ of the population, ${ }^{29}$ might fail to accrue benefit from oral rehydration if gastric stasis prevented them from absorbing their drink. We found no evidence of any impact of these confounding variables on performance.

We have seen the evidence that rehydration did occur with both water and the sports drink in the form of weight changes, increased urine output and decreased subjective measures of thirst. Without difference between the two drinks, we cannot recognise any beneficial effect of sodium/glucose cotransport in our data.

We estimated the percentage dehydration caused by the swimming sessions at $0.42 \%$. This may be an underestimate as we believe that some postswim weights were increased by water retained in the swimmer's hair. We considered the possibility that water had been absorbed through the skin. Published rates of skin water absorption ${ }^{30}$ would have our subjects absorbing $35 \mathrm{~mL}$ of water over the session, explaining only $10 \%$ of the anomaly. Nonetheless, our data are consistent with all drinking groups demonstrating a degree of overcorrection of their dehydration in the course of the swimming session.

Our findings are consistent with a recent study of ad libitum drinking in a $40 \mathrm{~km}$ ergometer cycle time trial, where $1.2 \%$ dehydration did not result in slower cycling times. ${ }^{31}$ They contrast with those of a 1985 study of adults' running performance at 1.5 to $10 \mathrm{~km}$ where dehydration of approximately $2 \%$ was achieved by pretreatment with frusemide where slower running times were seen in the dehydrated runs. ${ }^{32}$ They also contrast with a 2010 adult study where $12 \mathrm{~km}$ runs in $26^{\circ} \mathrm{C}$ ambient temperature reported slower run times in runners who were dehydrated at the start of exercise. ${ }^{33}$ Dehydration rather than during-exercise drinking regimen had been the focus of these studies on runners, and they do not provide evidence of drinking improving performance. 


\section{CONCLUSIONS}

We conclude that drinking during exercise does increase hydration, but not performance. Neither sports drink nor water confers a physiological advantage that improves performance in sustained aquatic exercise over $105 \mathrm{~min}$ despite such exercise producing at least $0.42 \%$ dehydration. This level of dehydration does not reach the $2 \%$ impaired performance threshold advocated by advisors to international sporting bodies. ${ }^{12}$ However, the intensity of our study subject's exercise exceeds the recommended minimum level of exercise for health in children. ${ }^{34}$ As they had no benefit from these drinks, we are confident that this will be the case at lower exercise intensity. We do not endorse the use of during-exercise rehydration nor of sports drinks in the paediatric population.

Contributors GLB designed and managed the study, analysed the data and wrote the manuscript. AL, AT and GSG designed and conducted the timing data collection strategy. SP and PM contributed to the planning and collection of subject data. DP designed the training regimes and contributed to the design of the study. FEW was the study randomiser. All authors contributed to the manuscript and approved the final manuscript. G John performed biochemical analysis on the study drinks. $R$ Reading, P Clarke and members of the Medical Advisory Committee of the Amateur Swimming Association made helpful comments on the manuscript.

Competing interests None declared.

Ethics approval The study was approved by Faculty of Medicine and Health Sciences Research Ethics Committee at The University of East Anglia (Ref 2013/2014-55)

Provenance and peer review Not commissioned; externally peer reviewed.

Open Access This is an Open Access article distributed in accordance with the Creative Commons Attribution Non Commercial (CC BY-NC 4.0) license, which permits others to distribute, remix, adapt, build upon this work non-commercially, and license their derivative works on different terms, provided the original work is properly cited and the use is non-commercial. See: http://creativecommons.org/ licenses/by-nc/4.0/

(C) Article author(s) (or their employer(s) unless otherwise stated in the text of the article) 2017. All rights reserved. No commercial use is permitted unless otherwise expressly granted.

\section{REFERENCES}

1. Burke L, Coyle F, Maughan R. Nutrition for athletes: International Olympic Committee, 2003:1-19.

2. Sawka MN, Burke LM, Eichner ER, et al. American College of Sports Medicine position stand. Exercise and fluid replacement. Med Sci Sports Exerc 2007;39:377-90.

3. Coombes JS, Hamilton KL. The effectiveness of commercially available sports drinks. Sports Med 2000;29:181-209.

4. Maughan RJ. Fluid and electrolyte loss and replacement in exercise. $J$ Sports Sci 1991;9(Spec No):117-42.

5. Cohen D. The truth about sports drinks. BMJ 2012;345:e4737.

6. Heneghan C, Howick J, O'Neill B, et al. The evidence underpinning sports performance products: a systematic assessment. BMJ Open 2012;2:e001702.

7. González-Alonso J, Mora-Rodríguez R, Below PR, et al. Dehydration markedly impairs cardiovascular function in hyperthermic endurance athletes during exercise. J Appl Physiol 1997;82:1229-36.
8. Cheuvront SN, Carter R, Castellani JW, et al. Hypohydration impairs endurance exercise performance in temperate but not cold air. $J$ Appl Physiol 2005;99:1972-6.

9. Goulet ED. Effect of exercise-induced dehydration on endurance performance: evaluating the impact of exercise protocols on outcomes using a meta-analytic procedure. Br J Sports Med 2013;47:679-86.

10. Luliano S, Naughton G, Collier G, et al. Examination of the selfselected fluid intake practices by junior athletes during a simulated duathlon event. Int J Sport Nutr 1998;8:10-23.

11. Minehan MR, Riley MD, Burke LM. Effect of flavor and awareness of kilojoule content of drinks on preference and fluid balance in team sports. Int J Sport Nutr Exerc Metab 2002;12:81-92.

12. Wilk B, Timmons BW, Bar Or O. Voluntary fluid intake, hydration status, and aerobic performance of adolescent athletes in the heat. Appl Physiol Nutr Metab 2010;35:834-41.

13. Prado $\mathrm{E}$, Barroso $\mathrm{S}$, Gous $\mathrm{H}$, et al. Hydration state in swimmers after three different forms of hydric replacement in the city of Aracaju-SEBrazil. Fit Perf J 2009;8:218-25.

14. Sun JM, Chia JK, Aziz AR, et al. Dehydration rates and rehydration efficacy of water and sports drink during one hour of moderate intensity exercise in well-trained flatwater kayakers. Ann Acad Med Singapore 2008;37:261-5.

15. Rowland T. Fluid replacement requirements for child athletes. Sports Med 2011;41:279-88.

16. Cohen D. Sports drinks adverts are banned for false claims. BMJ 2014;348:g136.

17. Noakes TD, Goodwin N, Rayner BL, et al. Water intoxication: a possible complication during endurance exercise. Med Sci Sports Exerc 1985;17:370-5.

18. Noakes TD. Overconsumption of fluids by athletes. BMJ 2003;327:113-4.

19. Almond CS, Shin AY, Fortescue EB, et al. Hyponatremia among runners in the Boston Marathon. N Engl J Med 2005;352:1550-6.

20. Smith S. Marathon runner's death linked to excessive fluid intake. Boston Globe 2002 (accessed 13 Aug 2002).

21. WHO. Marketing of food and non-alcoholic beverages to children. 63rd World Health assembly. Geneva: World Health Organisation, 2010.

22. de Ruyter JC, Olthof MR, Seidell JC, et al. A trial of sugar-free or sugar-sweetened beverages and body weight in children. $N$ Engl $J$ Med 2012;367:1397-406.

23. Ludwig DS, Peterson KE, Gortmaker SL. Relation between consumption of sugar-sweetened drinks and childhood obesity: a prospective, observational analysis. Lancet 2001;357:505-8.

24. Malik VS, Schulze MB, Hu FB. Intake of sugar-sweetened beverages and weight gain: a systematic review. Am J Clin Nutr 2006:84:274-88.

25. Maughan RJ, Leiper JB. Limitations to fluid replacement during exercise. Can J Appl Physiol 1999;24:173-87.

26. Urbaniak GC, Plous S. Research Randomizer. Version 4.0. 2013.

27. Gurusamy KS, Gluud C, Nikolova D, et al. Assessment of risk of bias in randomized clinical trials in surgery. Br J Surg 2009;96:342-9.

28. Lassen K, Heye A, Myrmel T. Randomised trials in surgery: the burden of evidence. Rev Recent Clin Trials 2012;7:244-8.

29. Abu-Arafeh I, Russell G. Prevalence and clinical features of abdominal migraine compared with those of migraine headache. Arch Dis Child 1995;72:413-7.

30. Galey WR, Lonsdale HK, Nacht S. The in vitro permeability of skin and buccal mucosa to selected drugs and tritiated water. J Invest Dermatol 1976;67:713-7.

31. Berkulo MA, Bol S, Levels $\mathrm{K}$, et al. Ad-libitum drinking and performance during a $40-\mathrm{km}$ cycling time trial in the heat. Eur $\mathrm{J}$ Sport Sci 2016;16:213-20.

32. Armstrong LE, Costill DL, Fink WJ. Influence of diuretic-induced dehydration on competitive running performance. Med Sci Sports Exerc 1985;17:456-61.

33. Casa DJ, Stearns RL, Lopez RM, et al. Influence of hydration on physiological function and performance during trail running in the heat. J Athl Train 2010;45:147-56.

34. World Health Organisation. Global recommendations on physical activity for health. Geneva: WHO, 2010 